\title{
ESPAÇOS DE SUBJETIVIDADE NO DISCURSO LITERÁRIO-RELIGIOSO FALANDO COM DEUS, DE FREI JERÓNIMO BAÍA
}

Ricardo CELESTINO ${ }^{1}$

Resumo: Em contribuição aos estudos enunciativo-discursivos propostos pela Análise do Discurso, analisamos o discurso Falando com Deus, de Frei Jerónimo Baía, poeta e religioso seiscentista português. Examinamos os espaços de subjetividade presentes na amostra selecionada, que levam o enunciador a ressignificar a fé católica na confluência de dois campos discursivos: a teologia medieval e o pensamento filosófico científico. Frei Jerónimo Baía (1620-1688) nasceu em Coimbra e professorou no Convento de São Martinho de Tibães como membro da Ordem Beneditina. Sua obra poética encontra-se reunida nos Cancioneiros Fénix Renascida (1715-1728) e Postilhão de Apolo (1761). Discurso regulamentado pela instituição religiosa e pelas influências das práticas sociais seculares. Seus enunciados são desdobramentos individuais que estimulam efeitos de sentido diversos acerca dos dogmas contra-reformistas. As noções de subjetividade propostas nos estudos de Gilles Deleuze e Felix Guattari (1995), assim como as reflexões teórico-metodológicas sobre a cenografia, articuladas por Dominique Maingueneau (2008a, 2008b, 2011, 2015) nos auxiliam no exame dos espaços de subjetividade de nossa amostra. As noções oferecem um campo conceitual sobre a potência de variação da expressão humana e compreendem a subjetividade como uma produção fruto de encontros com o Outro, o que de certa forma contribui para as reflexões sobre interdiscursividade.

Palavras-chave: Barroco. Literatura. Análise do Discurso. Frei Jerónimo Baía. Efeitos de subjetividade.

\footnotetext{
${ }^{1}$ PUC - Pontifícia Universidade Católica - Programa de Estudos Pós-graduados em Língua Portuguesa. São Paulo - São-Paulo - Brasil. 05014-901 - $\underline{\text { ricardo.celestino2003@gmail.com }}$
} 


\section{Introdução}

No presente artigo, examinamos, com base nas categorias de cenografia e interdiscurso, propostas por Maingueneau (2008a, 2008b, 2011, 2015), e as reflexões sobre subjetividade de Deleuze e Guattari (1995), os efeitos de sentido presentes em Falando com Deus, de Frei Jerónimo Baía, pertencentes ao Barroco português.

Maingueneau (2008a) compreende o discurso como a prática enunciativa inserida em um determinado lugar institucionalizado socialmente. Apropria-se do conceito de formação discursiva (FOUCAULT, 2012; PECHÊUX, 2010) e propõe a categoria de interdiscurso, que afeta a discursividade para além da relação direta entre língua e história. Reflete que os enunciados de um discurso estabelecem uma relação dialógica (BAKHTIN, 1992) com práticas discursivas anteriores e categoriza esse encontro por meio de uma tríade constituída por universo, campos e espaços discursivos. Este diálogo permite a valorização dos aspectos sócio-histórico-culturais para a construção dos efeitos de sentido de um discurso, em nosso caso, de Falando com Deus, de Frei Jerónimo Baía.

Deleuze e Guattari (1995) são expoentes fundamentais na Filosofia Pósestruturalista. Selecionamos, dentre seus estudos, as reflexões sobre a subjetividade, com a finalidade de identificar espaços construídos pelo sujeito-enunciador na prática enunciativa que possibilitam a constituição de efeitos de sentido. A noção proposta pelos autores oferece um campo conceitual sobre a potência da variação da expressão humana, já que possibilitam que observemos a prática enunciativa e sua relação com o interdiscurso.

Nossa amostra de pesquisa é institucionalizada na Literatura Barroca e estabelece fronteiras com campos discursivos da Teologia Medieval e da Filosofia que começa a ser edificada no fim do século XVII e início do século XVIII, tendo seu apogeu em Descartes. Primeiramente, apresentamos as condições sócio-histórico-culturais do discurso literário barroco e suas articulações com a religiosidade, já que servem como referência interdiscursiva para análise de nossa amostra. Em seguida, depreendemos sobre as categorias de interdiscurso e cenografia, refletidas por Maingueneau (2008a, 2008b) e a subjetividade proposta por Deleuze e Guattari (1995) que permitem examinarmos espaços de subjetividade presentes na amostra selecionada, que levam o enunciador a ressignificar a fé católica na confluência dos campos discursivos supracitados. 


\section{A institucionalização da Literatura no século XVII}

O que se considerou discurso literário seiscentista corresponde à reinterpretação de tópicas da retórica clássica, destacando especialmente as obras aristotélicas. Aristóteles (1998) teve influência significativa na retórica e na poética europeia até o século XVIII, passando por épocas de descrédito e outras de grande prestígio. No século XVII, as composições líricas e as contrafações jocosas se constituíram a partir do sistema retórico poético aristotélico. Fundamentado na concepção imitava como base da composição enunciativo-discursiva, o enunciador seiscentista persegue o modelo da agudeza, estratégia que busca a congruência entre as coisas e sua representação por palavras.

Inúmeros tratadistas do final do século XVI e início do século XVII observam que a obra seiscentista não diz a verdade da coisa, mas finge sua verossimilhança e é legitimada racionalmente. A imitação tende a provocar a adesão do coenunciador e esse artifício encontra reflexo no discurso literário que se apropria das artes poéticas e retóricas clássicas. A busca pela verossimilhança consiste em estratégia que articula a congruência entre a coisa pensada e a forma com que aparece na prática enunciativa e detém efeitos de sentido ao coenunciador. Signo de confiabilidade da relação palavra e pensamento, a verossimilhança é um componente de adequação do discurso literário seiscentista entre enunciador e coenunciador, já que inclui os afetos que se deseja acionar, o conjunto de paixões, as reações vitais dominadas pelo mundo simbólico das palavras.

O ato de despertar paixões no Outro atribui-se, para Carvalho (2007), também à retórica aristotélica. O discurso literário seiscentista usa da palavra como instrumento de ação prática, fruto da convergência ou proximidade da retórica e da poética que, dada a junção, categorizam-se em empregos: da linguagem especulativa - adequação da expressão à matéria; da linguagem dialética - tem no verossímil a garantia para a argumentação persuasiva que apresenta provas e aciona afetos - e da linguagem poética - serve a efeitos de controle moral das convicções e dos desejos. Tais empregos condicionam a linguagem a um processo de adesão crível ao discurso enunciado. $\mathrm{O}$ uso poético no desenvolvimento dos enunciados encontra-se na palavra imitativa, que promove no coenunciador o deleite pela semelhança congruente entre coisas e nomes. 
Ser enunciador de um discurso literário implica ter a habilidade de promover na prática enunciativo-discursiva esse tipo de efeito imitativo. Carvalho (2007) observa tratar-se de engenhoso aquele que tem boas habilidades no lapidar das palavras, dos nomes, dos verbos, da construção bem-feita de silogismos, unindo código linguageiro e

pluralidade cultural e social. Nesse sentido, o emprego das metáforas é princípio da imitação, já que pressupõe a percepção das semelhanças por parte do coenunciador.

\section{A religiosidade no discurso literário seiscentista}

A arte seiscentista explora muitas tópicas do universo bíblico, imitando seus temas e muitas vezes a essência mística de sua cenografia. Portugueses cultores como Frei Agostinho da Cruz, Maria do Céu, Frei Jerónimo Baía e Frei Antonio das Chagas são exemplos de praticantes dessas estratégias, ao conceberem em seus textos uma moralização geral que relaciona, muitas vezes, a natureza humana e o direcionamento moral do cristianismo. Em especial, Frei Antonio das Chagas explora, por exemplo, pontos fulcrais da paixão de Cristo em Cartas Espirituais.

A simbologia religiosa é o que aproxima a prosa seiscentista ao divino místico presente na prosa teológica. Belchior (1971) observa que tanto poesia como prosa estão suscetíveis muitas vezes ao místico quando há a tentativa de expressão de uma experiência divina, extraordinária e inefável do enunciador com Deus ou a Verdade. As relações entre o sacro e o profano se dão, assim, em duas vias: primeiramente, a escrita secular relaciona-se com o simbólico religioso ao aproveitar o vocabulário e as rotinas culturais validadas tanto nas representações bíblicas quanto no mundo sensualizado; em segundo lugar, a influência que o discurso religioso exerce no provimento de lugares comuns, consolidados popularmente em descrições emotivas, representações afetivas de certas ideias-forca, sentimentos e experiências doutrinárias e de tradição religiosas sob corrente consuetudinária.

Belchior (1971) destaca que as expressões do sentimento religioso no discurso literário seiscentista se valem da associação com as experiências seculares. A prosa religiosa tem como pressuposto imitar a religiosidade mística e a secularidade dos poetas e cultores de sua contemporaneidade. Nem sempre, nos discursos religiosos seiscentistas, são as atividades místicas que levam ao caminho da mística cristã. Há influências da via escolástica, que prioriza a concorrência da razão como base para os atos humanos 
regulares, matriz do pensamento jesuíta seiscentista. Pela razão, chega-se ao transcendente divino e místico.

A alegoria nos tratados retóricos greco-latinos, para Carvalho (2007), funciona como ornato que consiste na transferência de um sentido outro para um sentido próprio em um enunciado. O sentido transferido emula uma figuração, que tem sentido próprio e uma ornamentação ofertada pela enunciação. Na prosa religiosa, é comum essa alegoria com o sacro, o mundano e o secular. O sentido próprio torna-se pressuposto daquele figurado e esse jogo advém de uma análise do próprio discurso bíblico que também realiza uma dicotomia de sentidos, sendo um espiritual e outro literal.

\section{Cenas da enunciação, interdiscurso e processos de subjetividade}

Ao falar de cenas da enunciação, Maingueneau (2008a) define tratar-se de uma categoria que permite ao analista observar a enunciação como interação em um espaço instituído. Definido pelos gêneros do discurso, as cenas da enunciação também constituem como dimensão construtiva do discurso que se coloca em cena a partir de três subcategorias: a cena englobante, a cena genérica e a cenografia.

Maingueneau (2015) observa que a cena englobante consiste na atribuição de um estatuto pragmático à pratica enunciativa: em nossa amostra de pesquisa, identificamos tratar-se de enunciados legitimados pelo tipo de discurso literário. Por sua vez, a cena genérica consiste na atribuição de papéis para seus parceiros, bem como os modos de inscrição no espaço e no tempo e a finalidade dos enunciados.

As cenas englobante e genérica oferecem quadro cênico para a cenografia. Maingueneau (2015) define a cenografia como a situação de enunciação distinta de marcas estilísticas, composicionais e temáticas que determinam as formas de enunciar o discurso. Em outras palavras, trata-se de uma categoria que permite ao analista examinar o dizer mostrado, o estilo e a estrutura dos enunciados.

Algumas práticas enunciativo-discursivas estão submetidas, devido à articulação de formações discursivas ${ }^{2}$, a um processo de subjetividade. Compreendemos que esse

\footnotetext{
${ }^{2}$ Foucault (2012) propõe o conceito de formação discursiva, com o intuito de organizar as proposições de efeitos de sentido possíveis de enunciados de uma determinada época. O enunciado reflete um real unívoco da frase que detém uma verdade defendida, um ponto de vista carregado de valores que se coadunam com
} 
processo é protagonizado por um sujeito do discurso, instância inscrita e construída na interação entre enunciador e coenunciador, sendo assim efeito de sentido possível, com vínculos de identidade com formações discursivas às quais faz referência. Para aprofundarmos esta noção, pautamo-nos nas reflexões de Deleuze e Guattari (1995) sobre os processos de subjetividade.

Os processos de subjetividade estão associados às diferentes formas de o sujeito do discurso mobilizar as formações discursivas que o constituem. Deleuze e Guattari (1995) também contribuem para refletirmos sobre a subjetividade nos discursos, ao apresentar o conceito de subjetividade como ferramenta teórica para refletir a experiência subjetiva. Em uma formação histórica específica, há um mecanismo de dobra realizado pelo sujeito que incide nos processos de construção de territórios existenciais individuais, o qual Deleuze e Guattari (1995) definem como subjetividade.

A subjetividade, para Deleuze e Guattari (1995), não significa a associação de um sujeito individual, mas sim um modo intensivo de produzir a curvatura de um certo tipo de forças sociais que, em nosso caso, influenciam na constituição dos discursos. Cada formação discursiva permite diferentes composições semânticas, já que, no caos interdiscursivo, sofre influência de outras formações discursivas que a atravessam, dando ao sujeito do discurso a mobilização de efeitos de sentido particularizados a cada ato enunciativo-discursivo.

Propondo a subjetividade como desdobramentos de forças sociais, Deleuze e Guattari (1995) contribuem para o estudo das relações possíveis entre indivíduo e mundo, afirmando que o mundo encontra-se virtualmente dobrado em cada alma, ou seja, em cada formação discursiva, e recupera a noção de mônada leibniziana para trabalhar a perspectiva da multiplicidade e de criação permanente no ato de desdobrar o mundo que existe na alma humana. Propõem, assim, dividir os desdobramentos da alma em quatro tipos, os quais apresentamos a seguir.

O primeiro, plano de imanência e o fora, trata-se do questionamento de que pensar pressupõe uma atividade constitutiva da interação entre dois planos que consistem na imanência e no fora. O plano da imanência pressupõe o solo onde se tece a imagem, os

os costumes específicos de uma cultura e sociedade. Tudo que é expresso em um determinado enunciado possui valor de verdade de um determinado grupo ou instituição social. Assim, os enunciados são influenciados por formações discursivas que advém de uma conjuntura histórico-social. Posteriormente, Maingueneau (2008a) organiza as formações discursivas em categorias que constituem o interdiscurso, sendo elas o universo, os campos e os espaços discursivos. 
conceitos, uma condição de possibilidade do próprio pensamento. Deleuze e Guattari (1995) compreendem como uma atividade natural, um ato involuntário com relação direta com o fora. O fora, por sua vez, é uma máquina abstrata que emite singularidades e envolve o movimento infinito do pensamento. O plano da imanência é como uma espécie de topologia traçada a partir de emissões singulares de pensamento sobre o fora. Pensar, dessa maneira, é uma potência de invenção dentro de um sistema de coerções dadas, que chamamos de universo discursivo que constitui uma época.

A segunda conceituação é fundamentada por Deleuze e Guattari (1995), a partir de uma retomada do projeto sobre meios de confinamento de Foucault (2012). Trata-se da reflexão sobre o movimento social de concentrar, repartir no espaço, ordenar no tempo e compor no espaço-tempo. Foucault (2012) observa que o sujeito é fruto de uma lógica disciplinar, já que se instaura em um ambiente fechado e está disponível a regras de visibilidade e segmentariedade. Deleuze e Guattari (1995) compreendem que há uma disciplina social que fabrica sujeitos, a partir de um poder que o toma como objeto e instrumento de um certo exercício de poder. No interior de um espaço disciplinar, encontra-se a individualização e a vigilância, que são indispensáveis na garantia de eficácia e consolidação de um modo de vida. Para Foucault (2012), poder disciplinar significa vincular cada sujeito a uma identidade bem determinada e criar a ideia de uma disciplina privatizada. Podemos ampliar essa concepção, quando pensamos na relação sujeito e espaços discursivos em Análise do Discurso, onde cada espaço detém um conjunto de regras pautadas no arquivo, fruto da memória discursiva das variadas formações discursivas que formam um espaço específico.

A relação entre a primeira e a segunda dobra são complementares. A primeira consiste em estabelecer um espaço disciplinar do pensamento. A segunda estabelece a recorrência de um modelo de racionalidade organizado em torno de uma regra de equivalência geral. Deleuze e Guattari (1995) compreendem que há nessa junção universos de valor em torno de grupos sociais específicos, fruto da segmentação de forças. A dobra, ou os desdobramentos subjetivos no discurso, será territorializada tanto pelo enunciador quanto pelo coenunciador.

Deleuze e Guattari (1995) observam que a subjetivação está ligada à busca de uma estabilidade subjetiva em torno de uma relação consigo mesmo. Toda produção de subjetividade é coextensiva à produção de um campo discursivo e também na 
interincompreensão com outros campos. A invenção de um novo território fundado sobre a noção de indivíduo nos leva a observar que há a constituição do principal dispositivo que possibilita os desdobramentos de forças de fora na produção de um novo tipo de relação consigo ou de plano de imanência.

No terceiro, Deleuze e Guattari (1995) propõem um regime de verdade ou reconhecimento do sujeito-individual. Trata-se de depreender um conjunto de regras que distingue o falso do verdadeiro e vincula o verdadeiro a um local de poder. Não há relação de poder, para o autor, sem uma relação com um campo específico do saber. O saber é essencial para um regime de poder e verdade para uma formação discursiva. Assim, a terceira dobra consiste na sobra do saber, da verdade e da relação do verdadeiro com o ser e o ser com a verdade. É nesse nível de constituição individual e subjetiva que se instauram as polêmicas em torno da construção de diferentes sentidos que um enunciador pode fazer do discurso ou das formações discursivas do Outro. Deleuze e Guattari (1995) observam que há uma atualização, ou versificação, nas condições sócio-históricas de produção na relação entre saber, poder e verdade. A ideia de sujeito pressupõe uma constituição a partir do processo de subjetividade pautada à questão que concerne ao posicionamento do sujeito oriundo de uma certa herança. As relações psicológicas do sujeito constituem campo de saberes e práticas e, nesse sentido, temos um campo de coerções discursivas individual, no qual o sujeito-enunciador aceita ou nega formações discursivas que constituem campos e cria sua identidade dentro de um espaço institucional.

Por fim, no quarto e último tipo, Deleuze e Guattari (1995) propõem um movimento de dupla captura, que envolve a divisão entre o dentro e o fora e a garantia de operacionalidade desse novo modelo construído. A terceira dobra pressupõe um modelo de racionalidade que visa afirmar a posição de fundamento que ocupa o sujeito. Este modelo leva à criação de uma dicotomia, que podemos refletir como uma ampliação da polêmica proposta por Maingueneau (2006), pautada na relação entre sujeito-enunciador e sociedade. A relação entre saber e verdade corresponde à posição de fundamento do sujeito e a quarta dobra propõe um movimento de captura que busca aprisionar o indivíduo e a sociedade em uma espécie de armadilha semiótica de um pensamento referencial, que observamos como a relação entre arquivo, memória, formação discursiva e sujeito-enunciador. 
O pensamento referencial, para Deleuze e Guattari (1995), pressupõe que não é possível acessar o real absoluto, mas sim estabelecer relações entre um sistema de signos e o objeto referente. Reconhece-se, assim, o real sob uma forma preexistente do real, filtrada por alguém. A armadilha semiótica pressupõe que dada a proliferação de inúmeras formas de mediação entre o indivíduo e a sociedade, é possível alcançar algum real. Compreendemos, então, que a existência do sujeito-enunciador não é um fato natural, mas corresponde a uma certa relação entre o saber e a verdade instituída, o que está ligado a um modo de subjetivação específico. O sujeito-enunciador é responsável por criar uma regra de identidade entre o individual e o social, que o opõe e o aproxima de grupos sociais instituídos.

\section{Falando com Deus e os espaços de subjetividade no discurso de Baía}

O século XVII é potencialmente um período de intensa produção literárioreligiosa. Frei Jerónimo Baia está entre os cultores de destaque da época, que dedica sua obra literária a propagar aspectos doutrinários da fé cristã. Podemos identificar, no discurso Falando com Deus, marcas dessa trajetória que, pela complexidade do tempo histórico, já que o enunciador encontra-se entre a emancipação da Filosofia enquanto ciência do pensamento e o declínio da Teologia como foco do saber, consideramos prospecto da subjetividade em que se encontra o sujeito-enunciador, dedicado a depreender sobre o seu complexo lugar no mundo cristão, como observamos na amostra selecionada abaixo:

\section{Falando com Deus}

Só vos conhece, amor, quem se conhece; Só vos entende bem quem bem se entende; Só quem se ofende a si, não vos ofende, E só vos pode amar quem se aborrece.

Só quem se mortifica em vós floresce; Só é Senhor de si quem se vos rende; Só sabe pretender quem vos pretende, E só sobe por nós quem por vós desce.

Quem tudo por vós perde, tudo ganha, Pois tudo quanto há, tudo em vós cabe. Ditoso quem no vosso amor se inflama, 
Pois faz troca tão alta e tão estranha.

Mas só vos pode amar o que vos sabe,

Só vos pode saber o que vos ama.

A amostra selecionada é classificada pela Crítica Literária como Soneto. Encontra-se publicada na antologia poética Fenix Renascida, que reúne os principais poetas e cultores do século XVII. Contudo, tomamos a amostra como prática enunciativodiscursiva que estabelece relações contratuais entre enunciador e coenunciador próximas do gênero confissão.

A confissão é um gênero muito utilizado pela Filosofia Medieval e Moderna, introduzida por Santo Agostinho no Cristianismo primitivo, que tem como finalidade estabelecer diálogo direto entre o enunciador e Deus. Trata-se de um gênero que, a partir desse contato, busca disseminar um valor moralizador acerca da relação entre a vida secular e a vida espiritual. Em Confissões, Santo Agostinho constrói sua obra a partir da relação entre a vida secular que abre mão e a vida espiritual que se apega após tornar-se cristão. A cenografia do gênero confissão na amostra selecionada potencializa um enunciador que conversa com dois potenciais coenunciadores: Deus e os fiéis cristãos.

Selecionamos a interdiscursividade entre a amostra selecionada e a obra Confissões como formação discursiva que referencia a prática enunciativa à imanência semântica da teologia cristã agostiniana. Poderíamos tomar a construção de sentido a partir de outros referenciais teológicos como o embricamento entre a teologia natural e a teologia cristã tomista, ou ainda nos fundamentos da teologia moral. A seleção da perspectiva agostiniana potencializada em nossa amostra justifica-se por uma das funções identificadas no discurso que é propor Deus como instância ao mesmo tempo próxima, já que é confessável, também distante, quando atribui-se a Ele uma potência racional transcendente.

Inicialmente, destacamos na amostra selecionada o fato de o enunciador organizar, a partir de um diálogo direto com Deus, os enunciados que dão título ao discurso: Falando com Deus. Falar diretamente com Deus pressupõe um dos atos de interlocução no qual há, simultaneamente, troca de papéis entre aquele que fala e aquele que escuta. Nesse sentido, Deus é ouvinte e o enunciador assume a função daquele que lhe dirige a palavra. 
O diálogo que o enunciador promove não é apenas entre ele e Deus. A aproximação com Deus é um gesto de autoconhecimento espiritual do enunciador, ao mesmo tempo que tem também caráter doutrinário ao coenunciador fiel cristão. Em enunciados como Só vos conhece, amor, quem se conhece, Só vos entende bem quem bem se entende e Só quem se ofende a si, não vos ofende, o enunciador dirige-se a Deus pelo uso de vos, enquanto articula uma coenunciação com o fiel nas implicaturas contidas em cada enunciado: tanto o enunciador quanto o coenunciador fiel deve se conhecer para conhecer Deus, deve se entender para entender Deus e pode ofender-se, mas jamais ofender a Deus.

O enunciador marca a necessidade de aproximação a Deus também para desfrutar da felicidade e da harmonia com o mundo e dele fruir experiências positivas. Em enunciados como "Só quem se mortifica em vós floresce, só é senhor de si quem se vos rende, só sabe pretender quem vos pretende” e “e só sobe por nós quem por vós desce”, a correlação de mortifica e floresce, Senhor de si e rende, sabe pretender e pretende, sobe e desce apontam para um território que não desvirtua o que é previsto na teologia agostiana, mas a reatualiza conforme o olhar proposto pelo enunciador. Identificamos que ao relacionar mortifica e floresce, há a retomada do renascimento após a morte não relacionado ao corpo, mas à mente humana e a sua capacidade de reformular eventos e experiências. Em senhor de si e por vós se rende, observamos que o enunciador propõe o caminho a Deus pela redenção. Não se trata de render aos símbolos institucionalizados pelas religiões, mas ao conceito místico que ele busca construir ao longo do discurso: aquele traz clareza e felicidade, iluminação transcendente ao mundo dos homens. O jogo de conceitos promovido pelo enunciador reforça, assim, uma visão agostiniana do mundo, que pressupõe em sua doutrina:

[...] é desse modo que peregrinamos para Deus nesta vida mortal (2Cor 5,6). Se queremos voltar à pátria, lá onde poderemos ser felizes, havemos de usar deste mundo, mas não fruirmos dele. Por meio das coisas criadas, contemplemos os invisíveis de Deus (Rm, 1,20), isto é, por meio dos bens corporais e temporais, procuremos conseguir as realidades espirituais e eternas. (AGOSTINHO, 2012, p. 4)

A doutrina cristã agostiniana também pode ser retomada nos enunciados seguintes. O enunciado mortificar relaciona-se ao ato de castigar-se ao mesmo tempo que se entorpecer diante de algo. No século XVII, o castigo pode relacionar-se ao ato de abrir 
mão das ofertas seculares e voltar-se à vida monástica de contemplação religiosa. Nesse sentido, entorpecer-se pressupõe o ato de desfrutar das experiências transcendentais do divino, o que reflete no florescimento espiritual.

A ausência de fruição e necessidade de contemplar Deus na vida mortal, propostos pela doutrina cristã agostiniana, pode ser retomada nos enunciados “Quem tudo por vós perde, ganha, pois tudo quanto há, tudo em vós cabe.” e “Ditoso quem no vosso amor se inflama”. Identificamos que o enunciador busca orientar para si e para seu fiel que, embora certos caminhos possam ser dificultosos na vida mortal, não são dolorosos quando há o apego divino. Quando se tem o comprometimento de falar com Deus, todos os desprazeres e fruições do mundo ganham novas leituras, já que todas as experiências mundanas são potencialidades para enriquecer a Alma. Se todas as coisas, sejam más ou boas, são criações de Deus, enxergamos Deus a todas elas e podemos contemplá-lo em cada uma delas quando se tornam acontecimentos.

Trata-se, nesse sentido, de uma contraposição à visão de mundo promovida pelos maniqueístas que certificavam as experiências humanas na dualidade bem e mal. Nos enunciados destacados, todo o esforço conceptista sobre o bem e o mal está no olhar que o fiel atribui às experiências que vive. Apegar-se a Deus garante um olhar construtivo da existência humana, já que todas as coisas são justificáveis em uma missão desconhecida pela razão mundana, mas muito claras à razão divina. Em outras palavras, Deus possibilita ao enunciador a capacidade de criar conceitos sobre a vida, assim como reformulá-los cotidianamente, na busca por uma razão que não se faz empírica, mas espiritual.

Dessa maneira, as influências agostinianas na construção de sentidos do discurso em análise nos leva a identificar uma reflexão acerca da razão divina no discurso. Em enunciados como "pois faz troca tão alta e tão estranha., mas só vos pode amar o que vos sabe, e só vos pode saber o que vos ama”, notamos o esforço que o enunciador tem em refletir, através de uma empreitada transcendente, que o fato de unir-se ao caminho de Deus torna a vida cotidiana mais racional. A noção de razão é desdobrada como novo território na prática enunciativa: não é aquela do método proposto de homem para homem, mas do método proposto de Deus para homem. Em outras palavras, Deus possibilita ao enunciador a capacidade de criar conceitos sobre a vida, assim como reformulá-los cotidianamente, na busca por uma razão que não se faz empírica, mas espiritual. 
Identificamos, na potência dos enunciados em gerar efeitos de sentido tão diversificados, a consolidação de uma mônada defendida por Deleuze (1995) como o caminho para a consolidação de espaços de subjetividade. A articulação lógica dos enunciados que, interligados, nos remetem a uma explicação quase científica dos caminhos espirituais a serem seguidos é estimulada por uma iluminação íntima e metafísica do enunciador. O discurso aborda, dentre tantas reflexões, o ato de leitura do mundo sob a revelação divina que se dá constantemente na alma do fiel, devido aos atos de apego a Deus e às doutrinas católicas. A instância Deus, nesse sentido, é o desdobramento de uma lógica racional-científica e uma lógica racional-teológica. Deus existe como instância alegórica no empirismo cientifico e como corpo maior, de iluminação transcendente na razão divina. Dessa forma, o enunciador oferta ao coenunciador um vasto espaço de articulação de formações discursivas que tomamos em nosso arcabouço teórico como espaços de subjetividade.

\section{Considerações finais}

A subjetividade é refletida em nossa pesquisa como um campo conceitual que analisa a potência da variação da expressão humana. Em Falando com Deus, observamos que a prática enunciativo-discursiva, a partir de seus encontros com outras formações discursivas, disponibiliza material complexo para a análise de múltiplos efeitos de sentido. Dessa maneira, apropriarmo-nos de Deleuze e Guattari (1995) parece-nos enriquecer os estudos sobre os efeitos de subjetividade na amostra selecionada, já que, em linhas gerais, as reflexões dos autores nos oferecem a possibilidade de desenhar uma possível categoria que se debruça ainda mais sobre a relação prática enunciativodiscursiva e as formações discursivas em Falando com Deus. Ao mesmo tempo que o enunciador propõe uma aproximação do coenunciador a um Deus católico e contrareformista, também nos deparamos com um aconselhamento que projeta ao orientado uma urgência de controle de si típica dos humanistas. Na prática enunciativodiscursiva, o enunciador encontra-se sob a influência de condições sócio-históricas de produção complexas, cujas formações discursivas são extremamente antagônicas, como o teocentrismo e o antropocentrismo. Contudo, sua capacidade de desdobrar as formações discursivas disponíveis no meio o capacita a construir uma noção de espiritualidade 
seiscentista que trafega entre dois domínios até então combativos: o teocentrismo e o antropocentrismo; o humanismo e a cultura medieval.

CELESTINO, Ricardo. Subjectivity spaces in literary-religious discourse Falando com Deus [Talking to God] by Friar Jerónimo Baía. Revista do Gel, v. 14, n. 1, p. 209-223, 2017.

Abstract: In contribution to the enunciation-discourse studies proposed by Discourse Analysis, we analyzed the discourse Falando com Deus, by the Friar Jerónimo Baia, a Portuguese poet and religious of the sixteenth-century. We examined the subjectivity spaces present in the sample selected, which lead the enunciator to reframe the Catholic faith at the confluence of two discursive fields: medieval theology and scientific philosophical thought. Friar Jerónimo Baía (1620-1688) was born in Coimbra and preached in the Monastery of São Martinho de Tibães as a member of the Benedictine Order. His poetic work is gathered in Songbooks Fenix Renascida (1715-1728) and Postilhão de Apolo (1761). A discourse regulated by the religious institution and the influences of secular social practices, its statements are individual developments stimulating different effects of sense about the counter-reformists dogmas. The subjectivity concepts proposed in studies of Gilles Deleuze and Felix Guattari (1995), as well as the theoretical and methodological reflections on the scenography, articulated by Dominique Maingueneau (2008a, 2008b, 2011, 2015), assist us in examining our sample subjectivity spaces. The concepts offer a conceptual field on the variation power of human expression and understand the subjectivity as a production resulted from meetings with the Other, which somehow contributes to the reflections on interdiscourse.

Keywords: Baroque. Literature. Discourse Analysis. Friar Jerónimo Baía, Subjectivity effects.

Submetido em: 22/04/2016.

Aceito em: 13/09/2016.

\section{Referências}

AGOSTINHO. A Doutrina Cristã. São Paulo: Paulus, 2002.

ARISTÓTELES. Poética. Tradução de Eudoro de Souza. 5. ed. Lisboa: Imprensa Nacional - Casa da Moeda, 1998.

BAKHTIN, M. Estética da criação verbal. São Paulo: Martins Fontes, 1992.

BELCHIOR, M. de L. Os homens e os livros (século XVI e XVII). Lisboa: Verbo, 1971. 
CARVAlho, M. do S. F. de. Poesia de agudeza em Portugal. São Paulo: Editora da Universidade de São Paulo, 2007.

DELEUZE, G.; GUATTARI, F. Mil Platôs: capitalismo e esquizofrenia. v. 1. Tradução de Aurélio Guerra Neto e Célia Pinto Costa. São Paulo: Editora 34, 1995.

FOUCAULT, M. A ordem do discurso: aula inaugural no Collège de France, pronunciada em 2 de dezembro de 1970. Tradução de Laura Fraga de Almeida Sampaio. 22. ed. São Paulo: Edições Loyola, 2012.

MAINGUENEAU, D. Cenas da Enunciação. São Paulo: Parábola, 2008a.

Gênese dos discursos. São Paulo: Parábola, 2008b.

Análise de Textos de Comunicação. 6. ed. São Paulo: Cortez, 2011.

Discurso e Análise do Discurso. Tradução de Sírio Possenti. São Paulo: Parábola Editorial, 2015.

PÊCHEUX, M. Por uma análise automática do discurso: uma introdução à obra de Michel Pêcheux. Campinas: Editora da UNICAMP, 2010. 